\title{
MERCADO INTERNO VERSUS \\ MERCADO COLONIAL EN LA PRIMERA \\ INDUSTRIALIZACIÓN ESPAÑOLA *
}

JOSEP M. DELGADO RIBAS

Universitat Autònoma de Barcelona

\section{RESUMEN}

La intención de este ensayo es analizar el papel del mercado hispanoamericano en el desarrollo de la industria española durante la segunda mitad del siglo xviI. En especial, se discute la visión tradicional que enfatiza la importancia del comercio colonial en el desarrollo de la industria algodonera moderna en Cataluña. Con el apoyo de investigaciones recientes se concluye que el mercado interior actuó de motor de arranque de la industrialización española.

\begin{abstract}
The aim of this essay is to analize the role of the Spanish American colonial market in the development of the Spanish industry during the second half of the XVIIIth century. Specially we discuss the traditional view wich emphasizes the importance of the colonial trade for the development of the modern cotton industry in Catalonia. With the support of new evidence furnished by recent research we conclude that the internal market was the engine of the Spanish industrialization.
\end{abstract}

\section{INTRODUCCIÓN}

El estudio de la relación entre las variables comercio de España con América Latina e industrialización española no es, ni mucho menos, un tema nuevo

* Este trabajo es un avance de la investigación financiada con cargo al proyecto DGICYT PB93-0858. Versiones preliminares han sido presentadas al VI Congreso de la Asociación de Historia Económica (San Sebastián, septiembre de 1993) y al 48th International Congress of Americanists (Estocolmo, julio de 1994). 
sino el capitulo mas reciente de un debate ya centenario que enfrenta a dos formas distintas de entender la evolución a largo plazo del estado español. Para un sector amplio de la historiografía nacionalista catalana, que pretendía demostrar la existencia de un monopolio exclusivo de la Corona de Castilla en el comercio americano, el triunfo de la industrialización moderna en el Principado fue una consecuencia lógica de la eliminación de todas las trabas legales con el Reglamento de 1778, del mismo modo que resultaba evidente que la decadencia de los siglos xvi y xvir había nacido de la anterior prohibición del tráfico con las colonias. Este planteamiento simplista seria puesto en evidencia por Vicens Vives y Pierre Vilar en diferentes trabajos publicados durante los años cincuenta y sesenta donde el llamado mito de la exclusión era certeramente derribado. Vilar y Vicens coincidian en destacar que la participación o no de catalanes en el comercio con las Indias debía interpretarse en función del dinamismo interno de la economía del Principado y que, en este sentido, las relaciones con el mundo colonial se intensificaron ya durante la segunda mitad del siglo xvil, dentro del proceso general de recuperación del sector exterior catalán. Trabajos posteriores de Fontana, E. Otte, Rafael Conde, Martínez Shaw y Cabrera Lobo, entre otros, demostraron la existencia de contactos indirectos y directos con la Contratación de Indias que, en algunos casos, se remontaban al siglo xvI 1.

Curiosamente, nadie llevó a cabo entonces una reflexión crítica sobre la otra premisa de la argumentación esgrimida por los historiógrafos de comienzos de siglo, a saber, que el comercio directo con América abrió a partir de 1778 un mercado de enormes posibilidades para la industria catalana que la burguesía emprendedora del Principado supo aprovechar para avanzar por la senda de la industrialización moderna ${ }^{2}$. Más bien al contrario, el peso de la evidencia empírica parecia seguir otro derrotero. Dos sólidos trabajos de investigación, presentados por C. Martínez Shaw y A. García Baquero al Primer Congreso de Historia Económica (Barcelona, 1972), aportaban pruebas de que el mercado colonial habia constituido el estimulo principal para el desarrollo del sector algodonero catalán durante el siglo xvir. Martínez Shaw establecía una correlación entre el despegue de la indianería y el incremento de la participación catalana en el comercio de Indias, «fenómenos en cierta medida paralelos», para «asegurar que el mercado americano contribuyó en gran medida a

\footnotetext{
1 Sobre estas cuestiones, Martínez Shaw (1986).

2 En palabras de Pere Voltes Bou, 1778 «fou quan la bandera de la matricula catalana onejà per primera vegda en els ports d'Amèrica que fins aleshores no havien pogut contemplar-la inmediatament s'alçaren gran nombre de fäbriques en el territori catalá: totes elles treballant per a Amèrican (1964, p. 14).
} 
acelerar el proceso de aparición de las primeras compañias de indianas y que prácticamente todas las grandes empresas estuvieron relacionadas con el mundo atlántico, mientras aquellas firmas modestas que basaron su comercio en una clientela primordialmente catalana no rebasaron nunca ciertos límites» ${ }^{3}$. Las relaciones entre las primeras manufacturas algodoneras y el comercio colonial eran «polivalentes». La actividad comercial proporcionó capitales para la inversión productiva y el mercado americano se habría configurado como una «salida privilegiada a la producción algodonera». Por su parte, García Baquero, con cifras elaboradas a partir de los registros de carga de los buques del comercio libre y sobre el presupuesto de partida de que el comercio catalán con América equivalía a las exportaciones efectuadas a través del puerto de Barcelona ${ }^{4}$, demostraba el «predominio del sector industrial en el conjunto de las exportaciones catalanas hacia las colonias» ${ }^{5}$ y ponía de relieve que «los pintados constituyen, después del aguardiente, el principal producto de exportación catalán» 6 . Pese a que en el texto García Baquero distinguía entre «lienzos pintados» - «tejidos diversos de lino y cáñamo importados del extranjero y tan sólo teñidos aquí»- $\mathrm{e}$ «indianas» - «producto totalmente fabricado en Cataluna $\gg-7$, y pese a reconocer que «los primeros superan a éstas en más de un 50 por cientom, las cifras que ofrecía en el cuadro 4 sumaban ambas partidas, sin ofrecer estimaciones más precisas sobre el peso relativo de cada una de ellas.

Los resultados dados a conocer por Martinez Shaw y Garcia Baquero ${ }^{8}$ reforzaron un modelo explicativo del crecimiento económico catalán del siglo xvin construido por Vicens Vives, Pierre Vilar y los primeros trabajos de Josep Fontana que interpretaba el acceso de la producción catalana al mercado colonial como la culminación de un proceso de mercantilización iniciado durante las últimas décadas de la centuria anterior que alcanzó su cenit en la antesala de las guerras coloniales de fines de siglo. Si para Vicens se produjo en este momento la aparición de la «tercera generación burguesa», que protagonizó «el salto definitivo del capitalismo comercial al industrial en Cataluña» ${ }^{9}$, Fon-

${ }^{3}$ Martinez Shaw (1974), p. 247.

4 García Baquero se proponia estudiar a través de los registros cerrados en el puerto de Barcelona «la estructura de este comercio de exportación colonial en el capitulo de los productos españoles» (1976, p. 287).

s Los porcentajes propuestos eran un $64 \%$ para la producción industrial y un $36 \%$ para la producción agraria. García Baquero (1976, p. 287).

6 Con un $58 \%$ de los textiles y un $26,8 \%$ de las exportaciones totales.

7 García Baquero identifica «indianas» y «cotones pintados», Cataluña (1976, p. 293).

${ }^{8}$ Mejor que nadie, el propio Garcia Baquero valoraba su aportación: «justo es reconocer que no ha venido a añadir gran cosa a lo ya sabido; más bien se ha limitado a corroborarlo, aunque, eso sí, a través de una óptica hasta ahora inéditam (1976, p. 294).

9 Vicens Vives (1974), p. 33. 
tana destacaba la importancia de las colonias como elemento potenciador «de una industrialización de tipo moderno, sobre todo en Cataluña», donde la debilidad del crecimiento a la británica se explicaba en función de la estrechez del mercado interno ${ }^{10} \mathrm{y}$ las transferencias en mercancías y dinero recibidas de América determinaban la precaria estabilidad de la economía española y del Estado Absoluto.

¿Qué papel correspondía a la demanda interna, catalana y española en este proceso de crecimiento orientado hacia el exterior? Uno más bien discreto, pues se vería obligada a relevar a fines del siglo xviII al «inmenso mercado colonial" ${ }^{11}$ en una coyuntura de crisis agraria poco favorable al crecimento del consumo de bienes de demanda elástica.

Frente a este modelo explicativo utilizado por la gran mayoría de los investigadores que abordaban la cuestión del nexo entre comercio colonial y crecimiento económico hasta comienzos de la década de los ochenta, sólo algunas voces se mantenían críticas. Jordi Nadal recordaba en 1970 la necesidad de no perder de vista la formación del mercado interior ${ }^{12}$, Fontana advertía sobre los peligros de una articulación excesivamente simplista entre industrialización y demanda americana ${ }^{13}$, y Maluquer de Motes, más rotundo, destacaba que era difícil de entender un proceso de industrialización que no comenzara a partir de la captura de la demanda interna. Su lectura de las cifras aportadas por García Baquero era completamente distinta a la efectuada por éste pues servía para destacar la escasa relevancia de las exportaciones enviadas a las colonias durante la etapa del «comercio libre». Según Maluquer de Motes, «las espléndidas oportunidades de acumulación que proporcionó a Cataluña el mercado americano en la segunda mitad del siglo xviI fueron, con seguridad, más amplias para la agricultura y el comercio que para la industria» ${ }^{14}$.

10 Fontana (1974), p. 73.

11 M. Izard (1976). Según Martínez Shaw, «la crisis que se precipita en 1793-1824 obligó a establecer un nuevo sistema comercial que iba de la mano de un nuevo sistema productivo. El hundimiento de los mercados americanos, primero por las guerras, posteriormente por la pérdida completa de las colonias en 1824, obligó a una reconversión general del sistema comercial espanol. Esto obligó a los productores de Cataluña y a los de las regiones más expansivas a buscar la apertura del mercado interior para sus productos» (1982, p. 55).

12 Nadal (1970). En el mismo sentido abundaba el hecho de que la producción algodonera de los años 1819-1820 sobrepasaba, pese a no contar ya con el apoyo del mercado colonial los niveles de 1792. Nadal (1975), pp. 191-194.

${ }^{13}$ Fontana (1976), p. 356. Fontana indicaba que un análisis en profundidad del proceso de consolidación de una industria moderna en Cataluña y su relación con el mercado americano no podia limitarse «a la simple verificación de la relación que existe entre comercio colonial y producción de tejidos» (p. 365).

14 Maluquer de Motes (1977), p. 75. 
Este ensayo pretende resituar el papel de la demanda americana en el desarrollo de la industria algodonera catalana a partir de tres líneas argumentales superpuestas: 1) una correcta lectura de las series de comercio con América reduce sensiblemente la participacion de los textiles de algodón catalanes en las exportaciones a las colonias; 2) la contabilidad de las empresas algodoneras confirma el reducido peso relativo de estas exportaciones sobre la producción total, y 3) ni el marco institucional dentro del cual se realizaba el comercio colonial durante el siglo XVIII, ni las pautas de consumo del mercado americano permitian una mayor penetración de las telas de algodón catalanas en el mercado ultramarino.

\section{ANTES Y DESPUÉS DEL «COMERCIO LIBRE»}

De entre las numerosas incógnitas que es necesario despejar para proceder a una correcta valoración del papel del mercado colonial en la consolidación del sector algodonero catalán, la primera y más elemental consiste en conocer la magnitud de las exportaciones de telas de algodón a las colonias a lo largo del siglo XviI, es decir, antes y después del «comercio libre».

Para la etapa del monopolio gaditano, la información disponible sobre las exportaciones de manufacturas al mercado americano apenas ofrece rastros de la presencia de indianas o cotones pintados en los registros de los buques ${ }^{15} \mathrm{de}$ la Carrera. De un modo genérico, el estudio de García Baquero sobre el comercio de exportación de Cádiz entre 1717 y 1778 no detecta la presencia de telas de algodón en las bodegas de los buques. Si nos referimos únicamente a las exportaciones catalanas a las Indias, el resultado no varia en exceso. Martínez Shaw apenas encuentra antes de 1756 indicios de la presencia de géneros de algodón en las consignaciones efectuadas por el comercio catalán ${ }^{16}$. En sus

15 Garcia Baquero (1976) I, pp. 319-322, y II, pp. 200-219. Frente a la mención repetida de lienzos, paños, bayetas y sederías en las relaciones de mercancias que cita, donde se contienen listas pormenorizadas de la producción industrial española y extranjera que se exportaba a Indias, o en los comentarios derivados del análisis de los registros de la Contratación, no aparece ni siquiera mención a telas de algodón, indianas, cotones pintados o cualquier otro término utilizado para detectar la presencia de géneros de algodón.

16 Martínez Shaw (1981), pp. 152-153, 157, 159-161, 166, 169-170, 174-178, 186-188, 192 193, donde se detallan los registros de carga de las embarcaciones catalanas que entre 1749 y 1756 participan en el comercio con América, no aparece ni una sola partida de telas de algodón. Esta impresión es confirmada asimismo en los apéndices donde se incluyen las mercancias embarcadas por los corresponsales catalanes en Cádiz en barcos no catalanes entre 1735 y 1756 (pp. 287-302) - ni una mención a indianas o géneros de algodón-, o en las cuentas de la Compañia Alegre y Gibert, en cuyo capitulo de exportaciones a Cádiz entre 1720 y 1754 aparece una única 
conclusiones al estudio de la estructura de las exportaciones, trasladará la carga de la prueba de la importancia del mercado americano para la industria al. godonera al período posterior:

en los años centrales de siglo, las remesas de indianas debían representar todavía un papel modesto dentro del conjunto de la exportación catalana a América, pero sin duda su presencia en la Carrera de Indias debió incrementarse a ritmo acelerado en las décadas siguientes ${ }^{17}$.

Sin embargo, las investigaciones realizadas por J. M. Oliva y Eloy Martín Corrales no confirman esas expectativas. El primero analiza la actividad exportadora de la Real Compañía de Comercio de Barcelona desplegada entre 1756 y 1785, para concluir que dentro de las exportaciones, «los tintados y teñidos son pocos, y menos aún los pintados» ${ }^{18}$. Por su parte Martin Corrales reafirma esta conclusión para el mismo período en las operaciones efectuadas por particulares ${ }^{19}$.

A conclusiones similares ha llegado recientemente J. K. J. Thomson en su reciente estudio sobre la indianería catalana, donde se discute la supuesta importancia del mercado colonial en la consolidación de la manufactura algodonera catalana. Para el período 1741-1758, observa no sólo que Madrid es ya su principal mercado ${ }^{20}$ en una estructura que ya incorpora toda la fachada litoral hasta Cádiz, sino que además la presencia de las telas de algodón catalanas ha iniciado la penetración en el resto del mercado interior. Thomson cree que las partidas remitidas durante estos años por los fabricantes catalanes a Andalucía se dirigian con preferencia a este mercado regional y no a las colonias. Pero, aun en el caso de que estas remesas tuvieran realmente por horizonte las colonias, "la producción para el mercado americano sería sólo de importancia secundaria» ${ }^{21}$. En las dos décadas siguientes, la estructura del mercado apenas registrará variaciones ${ }^{22}$. Thomson reproduce los datos de Asumpta Muset sobre las ventas de la fábrica $F_{c ̧}$ Ribas y Compañía entre

partida de 25 piezas de indianas remitidas en 1752 con el patrón Joan Bautista Balansó, que no representa ni una centésima parte del valor total de las exportaciones (pp. 333.343). Lo mismo se observa a partir de la contabilidad de Ermengol Gener para el periodo 1747-1756 - ausencia total de telas de algodón-, pp. 352.358.

17 Martínez Shaw (1981), p. 236.

18 Oliva Melgar (1987), pp. 268-269 y 274.

19 Martín Corrales (1988), pp. 125-144.

20 Sobre la relevancia de Madrid como gran centro consumidor de telas de algodón catalanas desde mediados del siglo xviI, Cruz (1994).

21 Thomson (1992), pp. 131-132.

22 Thomson, 1992, p. 163. 
1766-68 y 1774-83 que confirman el predominio del mercado interior, y dentro de él del castellano.

\section{CUADRO 1}

Ventas de las fábricas $F$ ç. Ribas $i$ Cia, Manel Ortells y Josep Castanyer (en \% sobre el total)

\begin{tabular}{|c|c|c|c|}
\hline Mercado & $\begin{array}{c}\operatorname{Ribas}^{23} \\
1766-1783\end{array}$ & $\begin{array}{c}\text { Ortells }{ }^{24} \\
1784-1796\end{array}$ & $\begin{array}{r}\text { Castanyer } \\
1780-1788\end{array}$ \\
\hline Castilla . & 53,27 & 51,3 & 33,42 \\
\hline Cataluña ... & 24,06 & s.d. & 37,20 \\
\hline Andalucia $\ldots \ldots \ldots \ldots$ & 5,80 & 26,0 & 17,38 \\
\hline Valencia $\ldots .$. & 5,34 & 7,9 & 3,66 \\
\hline Murcia $\ldots \ldots \ldots \ldots \ldots$ & 2,38 & 11,7 & 1,45 \\
\hline Pais Vasco ................. & 0,50 & 0,4 & 0,41 \\
\hline Aragón $\ldots \ldots \ldots \ldots \ldots \ldots$ & 0,69 & 1,2 & 0,72 \\
\hline 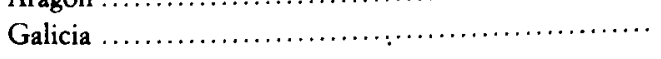 & 0,69 & 0,3 & 4,91 \\
\hline 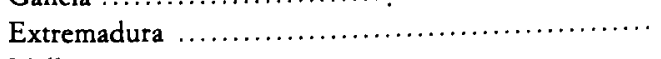 & 0,29 & 1,2 & 0,18 \\
\hline 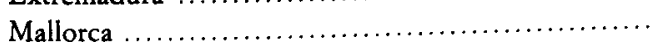 & 0,15 & - & - \\
\hline 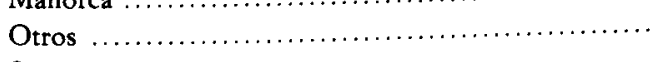 & 0,69 & - & 0,34 \\
\hline 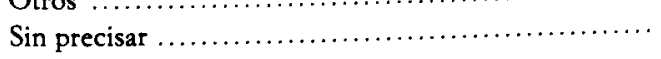 & 6,22 & - & 0,19 \\
\hline
\end{tabular}

Así pues, las evidencias empíricas que tenemos indican que, al menos hasta 1778 , la industria algodonera catalana necesitó poco o nada del mercado americano para consolidarse. En este momento existían 63 empresas algodoneras activas entre reguladas y no reguladas ${ }^{26}$, lo que representaba, sólo para el caso de las reguladas, 950-1.000 telares y una producción anual de 1,2-1,4 millones de metros ${ }^{27}$.

Estos resultados son importantes porque obligan a modificar la argumentación que defiende la importancia del mercado americano para la industria al-

${ }^{23}$ Muset (1988), p. 396, y Thomson (1992), p. 164. Falta la información correspondiente al periodo $1769-1773$.

24 Delgado Ribas (1988), p. 112. La información sobre las ventas de Ortells no recoge las operaciones en el mercado catalán. 1788.

${ }_{26}$ Thomson, 1992, pp. 188 y 194.

27 Thomson (1992), p. 197. 
godonera catalana en el periodo 1778-1796, es decir, en el marco del sistema de «comercio libre». En lugar de presentar esta etapa como la culminación lógica de un proceso gradual de conquista del mercado americano iniciada en la etapa anterior, es necesario ahora explicar qué factores provocaron, en espacio de pocos años, la reorientación del sector exportador hacia el mercado colonial.

Todas las estimaciones sobre las exportaciones de telas de algodón catalanas al mercado americano durante el «comercio libre» (1778-1808) han utilizado como soporte documental la misma fuente: los registros de carga de los buques elaborados en las aduanas habilitadas para el pago de aranceles y reales derechos. Recientemente ${ }^{28}$, y en una reelaboración de las cifras presentadas en 1972, García Baquero ha expuesto con claridad cuáles son sus criterios para establecer la distinción dentro de las exportaciones de manufacturas «nacionales» entre telas de algodón estampadas fabricadas en Cataluña y pintados sobre lienzo extranjero. Su estimación, que incrementa respecto a la mía de 198129 el peso de las indianas del Principado, se sustenta sobre un criterio taxonómico puramente terminológico. Las denominaciones «indiana» y «cotón pintado» se utilizan para distinguir las telas de procedencia genuinamente catalana, de los lienzos de procedencia foránea pintados en Cataluña y luego reexportados al mercado colonial ${ }^{30}$. Aceptar este criterio ofrece al investigador la ventaja de que reduce a la lectura de los registros el trabajo de separar las telas de lino de las de algodón y hace difícil la existencia de grandes discrepancias entre dos series construidas sobre la misma fuente ${ }^{31}$.

Pero el problema es mucho más complejo, especialmente por dos razones. En primer lugar, porque la distinción entre lienzo pintado de lino e indiana o cotón pintado que establecen las hojas de registro no constituye una información fiable para determinar el tipo de fibra de que están compuestos los tejidos. Los resúmenes de los registros del «comercio libre» no pretendían recoger las caracteristicas técnicas de las mercancías registradas, porque esta no fue nunca su función. Lo único que exigía la Real Hacienda al funcionario de rentas es que clasificara los géneros según las diferentes categorías fiscales recogidas en los Aranceles de 1778, a saber, géneros del reino libres, mercancías nacionales que pagaban el $3 \%$, y mercancias extranjeras al $7 \%$, en función de las

28 Garcia Baquero (1991).

29 Delgado Ribas (1981). La discusión en torno al volumen de las exportaciones de telas de algodón catalanas, en Delgado Ribas (1988) y (1993), Garcia Baquero (1991).

${ }^{30}$ Garcia Baquero (1991), p. 29.

31 Por ello considero razonable la perplejidad que manifiesta Garcia Baquero al comparar sus cifras con las mias. 
declaraciones de los cargadores ${ }^{32}$. Las dudas que las aduanas habilitadas exponían a la dirección general giraban en torno a la tributación de los géneros que los comerciantes presentaban para su oportuno registro y no respecto a la naturaleza de las fibras utilizadas en su fabricación. En segundo lugar, existe un problema conceptual común a todas lenguas que incorporaron en su léxico los términos «indiana», «pintado» o «calicot» para identificar a unos textiles inicialmente importados de Asia, pero que desde fines del siglo xvil comenzaron a ser imitados en Europa, no por la fibra empleada, sino en función de su técnica específica de acabado. Así, en su General Dictionary of Trade and Commerce, Malachy Postlethwayt definía el «calicoe» como «una variedad de manufactura de lino, hecha de algodón principalmente en las Indias Orientales» ${ }^{33}$. Un siglo después, otro diccionario inglés definirá la indiana como una «tela de lino o algodón, o de mezcla de uno y otro pintada por un solo lado» ${ }^{34}$. El mismo problema plantea el término «indienne» en la terminología francesa ${ }^{35}$. En Cataluña, la confusión era alimentada por los propios empresarios cuando, por ejemplo, se autocalificaban en un memorial presentado a Carlos III, como fabricantes de «indianas y demás lienzos pintados de algodón» ${ }^{36}$.

Aceptemos, por un momento, que la pericia de los agentes de aduana era suficiente como para distinguir la textura de un tejido sin desatar el fardo que

32 El Reglamento de 1778 especificaba, en su art. 8, que «Los mencionados Registros se han de formar en las Aduanas con total separación de los géneros y frutos Españoles, y de los efectos y mercaderias Extranjeras que nunca se podrán mezclar, y con expresión del aforo y adeudo de derechos exigidos de unos y otrosm.

Según manifestaba el administrador general de la aduana de Barcelona, Joaquín de Helguero no se realizaba la inspección ocular de los bultos embarcados por los comerciantes en los buques del «comercio libre» para no perjudicar «a los interesados o dueños de los fardos de telas y ropas, porque viniendo estos ya fardados y empaquetados desde las mismas fábricas si se hubiesen de reconocer por menor padecerian algún detrimento» (Helguero a la Dirección General de Rentas, Barcelona, 2 de marzo de 1794. AGS, DGR 2." r., leg. 819). De este modo debia resultar dificil el peritar si una pieza de tela estampada era de lienzo o algodón.

33 Postlethwayt, 1766, I. Según Eric Kerridge, el término "pintado» comenzó a utilizarse en el Lancashire a partir de la década de los veinte del siglo XVIII para designar un nuevo tipo de tejido elaborado por empresas como Weymouth, Melcombe Regis o Stepney. La novedad que representa el «pintado» inglés radica en que se trata del primer textil manufacturado fabricado integramente en algodón importado de las Indias Occidentales, y estampado siguiendo técnicas de impresión en bloque que imitaban a las empleadas en la India para la producción de telas «chintz». Kerridge (1985), pp. 125 y 223.

34 The Century Dictionary. An Enciclopedic Lexicon of the English Language, Nueva York, 1889, I, p. 764 .

35 «Les indiennes ont aussi été nommées toiles peintes parce que, dans le principe, à lexemple des Orientaux, les Europeéns exécutaient les dessins au moyen du pinceautage», Dictionnaire Français Illustré et Encyclopedie Universelle, vol II, Paris, C. Marpon y E. Flammarion Edits, s. f.

36 Los fabricantes... a Carlos III, Barcelona, 9 de noviembre de 1771, AGS, Superintendencia de Hacienda, leg. 1431. 
lo contenía. Entonces el criterio de García Baquero sería correcto siempre que todos lo cotones pintados e indianas embarcados en Barcelona como género «nacional» fueran, efectivamente, manufacturados en las fabricas catalanas. Pero esto no es cierto. El mismo Reglamento de 1778 en su art. 26 recordaba que los géneros de algodón llegados de Filipinas y luego reexportados al mercado americano tenian la consideración de género nacional sujeto al arancel del $3 \%$. Estas partidas no fueron importantes hasta la creación, por RC de 10 de marzo de 1785 de la Real Compañia de Filipinas, uno de cuyos principales negocios debía ser la importación de telas de algodón asiáticas al mercado español. No deja de ser significativo que las primeras remesas de indianas «de la India» llegaran a Cádiz durante el segundo semestre de 1787, y que su venta al mayoreo a los fabricantes de estampados comenzara a efectuarse en 1788 , fecha en que mis cifras y las de Antonio García Baquero comienzan a discrepar. $\mathrm{Y}$ estas importaciones no hicieron sino aumentar en los años siguientes. La Balanza de Comercio de 1792 indica que se introdujeron en España 1,7 millones de varas de telas de algodón procedentes de Filipinas. Pensar que una proporción importante de estos géneros fue absorbida por la industria de estampación catalana para su posterior reexportación a las colonias no es descabellado. Un informe elaborado por la misma Compañia de Filipinas a mediados de 1790 resumía las importaciones efectuadas durante el último semestre y su distribución en la Peninsula. Barcelona fue el destino final de 101.025 varas de lienzo de algodón en blanco (el 92,6\% del total), 150.000 varas de mahones en crudo $(52,1 \%), 5.187,5$ varas de muselinas $(26,4 \%)$ y 6.550 varas de gasas $(76,5 \%)$. La mayor parte de estas telas fue adquirida en la Lonja de Barcelona por los fabricantes de estampados para su posterior reexportación a las colonias ${ }^{37}$. Pese a ser ya importante no es este el único motivo de discrepancia entre las series de Garcia Baquero y las mías. En 1789 el ministro de Hacienda López de Lerena autorizó la introducción de muselinas extranjeras en crudo ${ }^{38}$. Según la balanza de comercio de 1792, entraron en Espa-

37 En Delgado Ribas, 1988, detecté la venta en la Lonja a través de los libros del corredor Just i Anglada de 300.593 varas de telas de la Compañia de Filipinas entre los años 1790 y 1792. Si se acepta que quedan recogidas aqui las operaciones de un $25 \%$ de los fabricantes de estampados, la cifra estimada de producción sobre telas asiáticas ascendería a 1,2 millones de varas, la mayoria, destinadas al mercado americano. La utilización de las telas de algodón importadas por la Compañia de Filipinas para la estampación de indianas destinadas al mercado colonial no fue exclusiva de Cataluña. Para El Puerto de Santa Maria, vid. J. J. Iglesias Rodríguez (1991), p. 232.

38 Las muselinas constituian la variedad mas fina de las telas de algodón importadas de la In. dia. La industria algodonera británica no estuvo en condiciones de competir con las importadas de Asia hasta que a fines de los años ochenta cuando la introducción de la «mule» y la llegada del algodón Sea Island garantizaron una mejora en la calidad y el descenso de los precios. En Catalu- 
ña 727.829 varas de muselinas importadas de Inglaterra, Italia y Francia, muchas de las cuales serian reexportadas al continente americano. Las telas de la Compañia de Filipinas y las muselinas procedentes de Europa eran, es cierto, géneros de algodón y asi se expresaba en el registro. Pero cuando de lo que se trata es de discernir qué parte de la producción algodonera catalana se orientó hacia el mercado colonial, el criterio taxonómico basado en el nombre es insuficiente. La única alternativa posible, que utilicé en 1981 y aún defiendo, es la de adoptar como único criterio seguro el arancelario utilizado por la dirección general de rentas para calcular la deuda tributaria de cada pieza de tejido: Mientras las indianas y telas de algodón catalanas eran libres del pago de derechos, las pintadas sobre lienzo o algodón extranjero, pese a exportarse también como efectos nacionales, pagaban una tarifa del $3 \% 39$.

Si dejamos a un lado esta cuestión, es posible encontrar aún otras dos líneas argumentales para sostener que la exportación de telas de algodón catalanas al mercado colonial durante el «comercio libre» fue más reducida de lo que piensa García Baquero. En primer lugar, el análisis de las «fuentes directas para la producción», que debe prevalecer sobre los resultados obtenidos a partir de la fuente «auxiliar» del comercio ${ }^{40}$, en caso de discrepancia. En segundo lugar, el estudio de las pautas de consumo, cuestión que los estudios sobre la formación del mercado en la época preindustrial han comenzado a prestar recientemente toda la atención que se merece.

Por desgracia, el libro de Thomson sobre la industria algodonera catalana no aporta información tan detallada respecto a la estructura del mercado como para el período anterior, aunque su conclusión es clara: «La expansión del mercado americano representó una atracción adicional, pero fue la existencia de unas conexiones de mercado más consolidadas y estables lo que representó el estímulo más poderoso para que los comerciantes inversores comprometieran sus recursos en una inversión industrial a largo plazo» ${ }^{41}$. Para compensar este vacio disponemos de información extraída de los libros contables de cuatro fábricas que producen indianas de algodón y lienzos pintados;

ña, la producción de muselinas tardaría aún en introducirse un par de décadas. Edwards (1967), pp. $40-43$.

39 El Reglamento de 1778 distingue entre manufacturas nacionales «pintadas o beneficiadas de modo que muden el aspecto, o el uso y destino que tenian al tiempo de su introducción, aunque

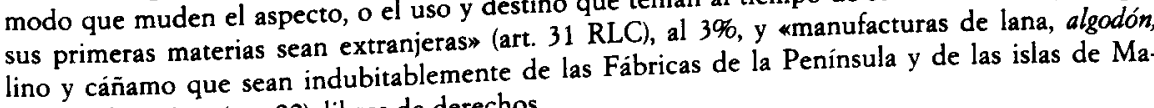
llorca y Canariasw (art. 22), libres de derechos.

40 Garcia Baquero, 1976, p. 270.

41 Thomson (1992), p. 216. 
las tres incluidas en el cuadro 1, Ribas, Ortells y Castanyer, más la firma Rull, estudiada por Alejandro Sánchez ${ }^{42}$.

\section{CUADRO 2}

Ventas de Josep Castanyer i Cia (1780-1788)

\begin{tabular}{|c|c|c|}
\hline & Libs. cat. & $\%$ \\
\hline Cataluña sin Barcelona ...... & 409.915 & 30,17 \\
\hline Barcelona ................... & 95.499 & 7,03 \\
\hline Castilla sin Madrid ........ & 276.389 & 20,34 \\
\hline 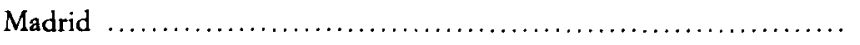 & 176.867 & 13,02 \\
\hline 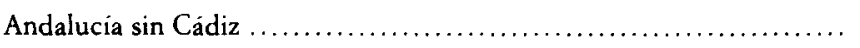 & 124.277 & 9,15 \\
\hline Cádiz $\ldots \ldots \ldots \ldots \ldots \ldots \ldots \ldots$ & 111.777 & 8,23 \\
\hline 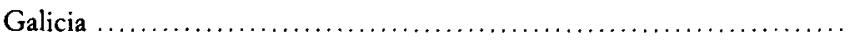 & 66.673 & 4,01 \\
\hline 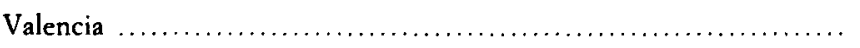 & 49.665 & 3,66 \\
\hline 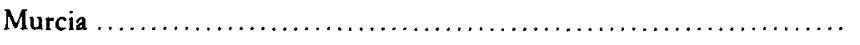 & 19.645 & 1,45 \\
\hline 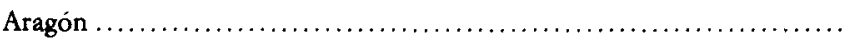 & 9.735 & 0,72 \\
\hline 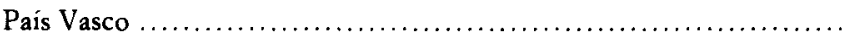 & 5.620 & 0,41 \\
\hline 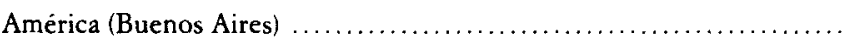 & 4.650 & 0,34 \\
\hline 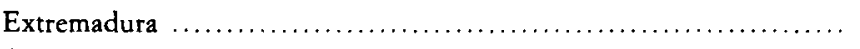 & 2.447 & 0,18 \\
\hline 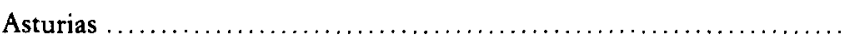 & 1.941 & 0,14 \\
\hline 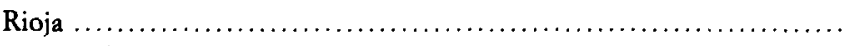 & 836 & 0,06 \\
\hline 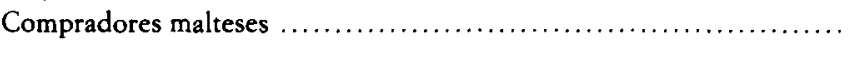 & 2.572 & 0,19 \\
\hline TOTAL .... & $1.358 .515^{43}$ & 100 \\
\hline
\end{tabular}

La contabilidad de las empresas de estampación confirma una distribución del consumo de sus manufacturas similar a la del periodo anterior al «comercio libre». El mercado castellano, en el cual Madrid juega un papel destacado, y el catalán absorben mas de dos tercios de la producción total. La nota discordante a esta situación de la firma Rull, cuyas ventas se dirigen según A. Sánchez en un $58,4 \%$ al mercado colonial, un $35 \%$ al catalán, y sólo el $6,6 \%$ al interior ${ }^{44}$, tiene, a mi entender, dos explicaciones. En primer lugar, el predominio de la estampación de lienzos importados $-75,7 \%$, frente al $24,3 \%$ de las telas de algodón - indicaría una especialización en el surtido del mercado

\footnotetext{
42 A. Sánchez (1989), pp. 18-20.

43 Incluye la suma de las fracciones (sueldos y dineros).

44 Sánchez (1989), p. 21.
} 
ultramarino. En segundo lugar, una cierta sobrevaloración del mercado colonial respecto al interior. A. Sánchez considera «claro» que la ventas a Cádiz tienen por destino último el mercado colonial, sin considerar que la bahía era la vía de entrada para la producción industrial catalana en la cuenca baja del Guadalquivir, un área de alta densidad urbana relativa, habitada por una población de renta notablemente superior a la media española y cuyo poder de compra no dejaría de atraer a los exportadores catalanes, como ya observara Thomson para el periodo anterior. «Sensu contrario», es presumible que una parte de las ventas al mercado catalán se destinaran a su distribución mediante la venta ambulante en el mercado interior. El grueso de las transacciones de la firma Castanyer en el mercado regional catalán - cuadro 2- se dirige hacia los centros nodales de las grandes diásporas mercantiles desplegadas por el comercio catalán en el mercado interior - Vic, Gironella, Tortellà, Copons y Calaf-, y no hacia los pueblos de la costa donde sólo Canet y Mataró tienen una participación modesta. Pienso que una parte de estas ventas viajaría en los carros que mantenían en funcionamiento las redes de distribución que conectaban estas villas catalanas y las españolas con presencia de «botiguers» catalanes ${ }^{45}$.

\section{PAUTAS DE CONSUMO Y RESTRICCIONES INSTITUCIONALES}

Pero ¿podría ser de otro modo?. Todas las informaciones descriptivas que he podido reunir insisten una y otra vez en que las indianas fabricadas en el Principado no se adaptaban al gusto de los consumidores de las colonias. Según Thomson, «los linos importados eran de mayor calidad y daban mejores resultados cuando eran estampados que las indianas de producción nacional» ${ }^{46}$; Alejandro Sánchez, por su parte, recoge el testimonio del comerciante matriculado Josep $F_{c ̧}$ Vila que añade nuevos elementos para explicar la preferencia hacia la estampación de lienzos importados:

las telas de Hamburgo y de otros paises extranjeros, que compran estos fabricantes para pintar y expedir a muchos pasages de América, en donde el lujo favorecido del clima a proscrito las de Algodón, conviene que sean francas de todos los derechos, para que pueden competir con las telas pintadas extranjeras

45 Sobre el funcionamiento de estas redes mercantiles en el caso de la pañeria, Torras Elías (1984), (1989), (1991).

46 Thomson (1992), p. 165 , n. 35 . 
y darlas a lo menos a los mismos precios a que resultan éstas, introducidas clandestinamente en América ${ }^{47}$.

En 1794, el administrador de la Aduana de Barcelona contestaba, a pregunta de la dirección general sobre la naturaleza de los estampados exportados por el Principado a las colonias que éstos se fabricaban sobre "platillas, caserillos aplatillados, diez y ochenos, veintenos y veintecuatrenos; cambrayones, o estopillas lisas, algunos cambrayes o batistas, choletas, lavales y trues, y de algodón, los elefantes, garras y gurras y algunas muselinas ordinarias» 48 .

La cantidad y la calidad de las telas exportadas desde la península a las Indias dependía en última instancia de la demanda americana. La demanda de textiles de las colonias era función de tres variables: las restricciones impuestas por el monopolio al libre comercio, las pautas de consumo de los hispanoamericanos y la existencia o no de producciones concurrentes que pudieran competir en precio, calidad y gusto con la oferta española.

Respecto a la primera cuestión, no voy a insistir en el hecho de que los textiles reexportados desde España resultaban más caros que sus equivalentes introducidos por el contrabando ${ }^{49}$, sino en el problema más genérico de los costes de transacción. Si prescindimos de aspectos puramente fiscales, el cargador español tropezaba con dos importantes restricciones a la hora de buscar el lucro en su participación en la Carrera de Indias que, pese a su naturaleza distinta, tenían como resultado la pérdida de todo control sobre la comercialización de las mercancías de demanda menos elástica y mayor margen de beneficio: el tabaco y los esclavos. Dejando al margen la problemática compleja del establecimiento del estanco del tabaco en América, la especificidad del sistema de provisión de negros a las colonias españolas constituye la gran diferencia entre el sistema colonial español y los restantes imperios europeos. Históricamente, la Corona había organizado la trata a través de contratos de asiento en virtud de los cuales el asentista recibía una concesión para introducir, durante un serie de años y en régimen de monopolio, una cantidad determinada de esclavos en una región determinada de la colonia. La Real Hacienda recibía una compensación por negro introducido que luego el asentista cargaba sobre el precio de venta al hacendado comprador de fuerza de trabajo esclava ${ }^{50}$. Este

47 Sánchez (1992), p. 220.

48 Helguero a la DGR, Barcelona, 27-XII-1794, AGS, DGR 2." r., leg. 819. Una relación muy similar, en Lipp (1793) I, pp. 203-205.

49 Esto ya lo sostenía J. F. Vila en 1786. Supra, nota 48. Sobre el extraordinario crecimiento del contrabando de telas de algodón en las colonias españolas después de 1778, S. J. Stein (1974).

50 La racionalidad del sistema de asientos no escapa a Mercedes García Rodríguez: «la cesión del Asiento proveyó a la corona española de recursos monetarios importantes, al establecer 
sistema restrictivo se mantuvo vigente hasta febrero de 1789 cuando, dentro del segundo ciclo reformista promovido por Floridablanca, el «comercio libre» se extendió también al tráfico de esclavos. Sin embargo, esta liberalización, que beneficiaba tanto a los negreros extranjeros como a los españoles, llegó tarde. El comercio español no tenía factorías en la costa africana, ni conocimientos en un negocio que alcanzaba altas cotas de riesgo e incertidumbre y las colonias españolas continuaron siendo abastecidas mayoritariamente por traficantes de otros paises hasta entrado el siglo XIX ${ }^{51}$. No pretendo sostener tanto que las restricciones impuestas por la administración española al tráfico de esclavos limitaran las posibilidades de beneficio del comercio colonial español como que, debido a ellas, éste no pudo organizar un sistema atlántico de intercambios 52. Sobre este "Atlantic System», caracterizado porque lo que circula en él son «esclavos, la producción de los esclavos, los "inputs" de las sociedades esclavistas y los bienes y servicios comprados con los beneficios del trabajo esclavo" 53 , se había construido la prosperidad del comercio colonial europeo.

Uno de los efectos multiplicadores que se derivaban de una participación directa en el sistema de intercambios atlántico era la captura de un mercado exterior de grandes dimensiones para la producción de estampados de algodón. En el comercio de la WIC holandesa con la costa africana «los textiles dominaron con claridad» hasta el punto de constituir el medio de pago en el $57 \%$ de las compras ${ }^{54}$. Para el caso británico, Richardson, Inikori y Eltis han destacado que la primera gran expansión de la industria algodonera británica que tuvo lugar entre 1748 y 1778 tuvo por horizonte el comercio de esclavos y la provisión de ropas bastas a las áreas de plantación más que el exigente mercado de consumidores blancos de la América anglosajona ". Para el caso francés, R. L. Stein ha señalado asimismo que en Nantes la fabricación de indianas nació y se desarrolló como resultado de la demanda de tejidos bastos

el cobro de altos derechos por la introducción de negros en sus colonias e imponer como condición irrevocable la subvención al tesoro español, por parte de la compañia concesionaria; además el monarca obtenía directamente un porcentaje de la ganancia total de la compañíam. García Rodriguez (1994), p. 299.

"Sobre esta etapa, Tornero Tinajero (1994).

52 Sobre esta cuestión me remito al volumen colectivo editado por Barbara Solow (1991).

"Solow (1991), p. 1.

54 Postma (1990), p. 104. En su mayoria lienzos de Leiden y Haarlem y telas asiáticas.

"s Richardson (1987), (1991); Inikori (1990), (1992). Segun Eltis, (1991) p. 106, en los años ochenta del siglo XVIII, las telas de algodón representaron el $56,4 \%$ en valor de las exportaciones británicas a la costa africana que se destinaron a la compra de esclavos; unos 9,5 millones de yardas ( 8,7 millones de metros). Sobre la conexión entre trata de esclavos y desarrollo de la industria algodonera en el caso de los Estados Unidos, Bailey (1992). 
y de baja calidad necesarios para vestir a los esclavos. Esta actividad industrial fue la más importante de la ciudad hasta la Revolución y «existió casi exclusivamente para servir al tráfico de esclavos» ${ }^{56}$. Uno de los principales atractivos que para los empresarios ingleses tuvo el Tratado de Eden (1786) fue la posibilidad de capturar el mercado negrero francés para la industria de Lancashire ${ }^{57}$.

Las pautas de consumo de la población americana no esclava tampoco jugaron en favor de la industria algodonera española. Como observa Mary Money, el uso de un determinado tipo de textiles va ligado a comportamientos culturales vinculados a la etnicidad. Peninsulares, criollos ${ }^{58}$, y en mucha menor medida, mulatos aparecen como los únicos consumidores «libres» de textiles importados. La indumentaria de la mujer criolla se hallaba desde fines del siglo XVII, y gracias a la extensión del contrabando, muy influenciada por el gusto francés: jubones de generoso escote confeccionados en bretañas, brocatos, rasos y paños de Castilla; casacas ceñidas de raso, sayas de seda -tisúes, tafetanes, rasos, felpas etc.-, mantones, mantillas y medias de seda, y ropa interior de lenceria fina y seda. La indumentaria de la mujer mestiza era sensible al efecto demostración y tendía a seguir los gustos franceses impuestos por las damas pudientes, aunque con telas de inferior calidad y menos recargadas de encajes, blondas y cintería: pollera amplia hasta la rodilla, jubón y manta de seda, y ropa interior de bretaña o muselina de algodón y seda.

La indumentaria masculina de los blancos acomodados también se caracterizaba por el predominio del diseño francés y el uso del lienzo, seda y lana como fibras textiles dominantes. El capote o gabán se confeccionaba en paños de Quito o bayetones "de Castilla» ${ }^{59}$, el calzón, de tafetán y paño, y la camisa de lencería europea. La única prenda masculina fabricada en telas estampadas fue el chaleco, también de influencia francesa, cuyo uso, sin embargo, sólo se generalizaria durante el siglo XIX.

Los hábitos de vestir de la población indigena y su resistencia a la aculturación varió en función de la jerarquia. Mientras las personas de linaje adoptaron al menos en la morfología las prendas europeas, como signo de diferenciación social, el común de los indios mantuvo su indumentaria tradicional. La

56 R. L. Stein (1979), pp. 134-135. También, Villiers (1991).

57 Inikori (1992), p. 167.

58 Money observa diferencias en cuanto a las pautas de consumo de los peninsulares y criollos más acomodados y el resto. Mientras los primeros tendian a vestir exclusivamente ropa importada, los segundos «se vieron obligados a confeccionar sus trajes mezclando con los tejidos hechos en los obrajes de esta ciudad (La Paz)m. Money (1983), p. 75.

59 En este caso, la expresión «de Castilla» indica que el género ha sido importado de la metrópoli. 
adopción de prendas como el medio calzón, camisa o chaleco, además de no ser inmediata y generalizada, no representó un aumento del consumo de textiles europeos porque estas prendas se confeccionaron con tocuyos y bayetas «de la tierra» 60.

Una via de aproximación al conocimiento de los niveles de consumo de textiles catalanes en América es la de utilizar los inventarios de tiendas establecidas en los principales centros urbanos de la colonia que comercializaban mercancía importada. En este sentido, los ejemplos que conocemos, que corresponden a centros regionales de cierta importancia como Valladolid de $\mathrm{Mi}$ choacán, Cusco, Lima y La Paz, en el Perú y Bolivia, ponen de relieve la escasa o nula presencia de indianas y telas algodón catalanas. El caso del corregidor de Canas y Canchis, estudiado por Neus Escandell ${ }^{61}$, propietario de una de las mayores tiendas de efectos europeos del Cusco es un ejemplo bien significativo. Sobre un inventario valorado en 1,6 millones de rs. vn. donde aparecen todos los productos de la manufactura europea transportados al mercado colonial, la ausencia de las indianas y tejidos de algodón catalanes es total.

\section{CONCLUSIÓN}

En las páginas precedentes he intentado refutar la teoría que liga el nacimiento de la industria algodonera catalana al desarrollo del mercado colonial durante la época del «despotismo ilustrado». Ni las cifras de que disponemos, ni las características del marco institucional en el que estaba inmerso el comercio con América, ni las pautas de consumo de los súbditos americanos de la corona permiten sostener actualmente esta hipótesis.

Seria incorrecto, sin embargo, extender el ejemplo de las telas de algodón catalanas al conjunto de la producción industrial del Principado. La construcción naval, el pintado de lienzos, las industrias papelera, mediera, sombrerera, y sedera, el curtido, la fabricación de encajes y puntas, el metal y la agroindustria generaron un importante valor añadido gracias a sus exportaciones al mercado americano. Muchas de estas actividades manufactureras prefabriles pudieron disfrutar además de toda la protección que el Reglamento de 1778 dispensaba a la «industria popular» y contribuyeron a incrementar el nivel de riqueza, bienestar y consumo de la Cataluña del último tercio del siglo XVIII.

60 Money (1983), pp. 169-172. También, en el Río de la Plata, Garavaglia y Wentzel (1989), y Nueva España, Menegus (1994).

61 Escandell Tur (1993) y (1994). 
Pese a que estos sectores industriales carecian de la capacidad transformadora y de arrastre que llevó a la industria algodonera británica a protagonizar la primera revolución industrial ya durante la segunda mitad del siglo xvIII, favorecieron el desarrollo de un tejido industrial denso y diversificado, capaz de aportar rentas de información, trabajo e iniciativa empresarial, a las nuevas oportunidades que se presentarán en la centuria siguiente y preparado para resistir el impacto de las malas coyunturas ${ }^{62}$.

\section{BIBLIOGRAFIA}

Austen, R. A., y SmITH, W. D. (1992): «Private Tooth Decay as Public Economic Virtue: The Slave Sugar Triangle, Consumerism, and European Industrialization», en J. E. InIKori y S. L. EnGerman (eds.), The Atlantic Slave Trade. Effects on Economies, Societies, and Peoples in Africa, the Americas, and Europe, Durham, pp. 183-204.

BaILEY, R. (1992): «The Slavery Trade and the Development of Capitalism in the United States: The Textile Industry in New Englandm, en J. E. INIKORI y S. L. ENGERman (eds.), The Atlantic Slave Trade.., Durham, pp. 205.246.

BREEN, T. (1986): «An empire of goods: the anglicization of colonial America, 1690. 1776m, Journal of British Studies, XXV (oct. 1986), pp. 467-499.

Cruz, J. (1994): «Approaches to Material Life and Household Consumption in Madrid (17th-19th centuries)". Comunicación a la sección Pautas de consumo en Hispanoamérica desde el siglo XVI, del 48 Congreso Internacional de Americanistas (Estocolmo).

DARITY, W. Jr. (1992): «British Industry and the West Indies Plantations», en J. E. INIKORI y S. L. Engerman (eds.), The Atlantic Slave Trade..., Durham, pp. 247-282.

Delgado Ribas, J. M.: (1982): «El impacto de las crisis coloniales en la economía catalana (1787-1807), en J. Fontana (ed.), La Economía Española al final del Antiguo Régimen. III: Comercio y Colonias, Madrid, pp. 99-169.

(1987): «El modelo catalán dentro del sistema de libre comercio», en El Comercio Libre entre España y América Latina, 1765-1824, Madrid, pp. 53-70.

(1988): «La industria algodonera catalana (1776-1796) y el mercado americano. Una reconsideración», Manuscrits, 7, pp. 103-116.

(1990): «De la filatura manual a la mecànica. Un capitol del desenvolupament de la indústria cotonera a Catalunya», Recerques, 23, pp. 161-179.

- (1992): «El impacto de la reforma del "comercio libre" sobre el comercio colonial españolm, en J. CASA (ed.), Economic Effects of the European Expansion, Stuttgart, pp. 387-434.

62 Pollard, 1991, 45-46. Thomson observa que una de las caracteristicas más acusadas de la economía catalana en el largo plazo fue su capacidad de aprovechar todos los periodos de expansión industrial y resistir a coyunturas depresivas que arrastraron a un irreversible declive a otras regiones manufactureras europeas (1992, p. 312). 
(1993): «"El algodón engaña”. Algunas reflexiones en torno al papel de la demanda americana en el desarrollo de la indianería catalana», Manuscrits, n. 11, pp. 61-83.

EDwards, M. M. (1967): The Growth of the British Cotton Trade 1780-1815. Nueva York.

ELns, David (1991): «Precolonial Western Africa and the Atlantic Economym, en B. Solow (edit). Slavery and the Rise of the Atlantic System, pp. 97-119.

Eltis, D., y Jennings, L. C. (1988): «Trade between Western Africa and the Atlantic World in the pre-Colonial Eram, American Historical Review, 93:4, pp. 936-959.

Escandell. Tur, N. (1993): Producción y comercio de tejidos coloniales. Cusco 1570-1820. Doctoral diss., University of California, San Diego.

- (1994): «Consumo de "tejidos de Castilla" y "ropa de la tierra" en Cusco y en los espacios mineros del Alto Perú durante el siglo xvitI», comunicación a la sección Pautas de consumo en Hispanoamérica desde el siglo XVIII, del 48 Congreso Internacional de Americanistas (Estocolmo).

FINE, B., y LEOPOLD, E. (1990): «Consumerism and the Industrial Revolution», Social History, 15:2, pp. 151-179.

FONTANA, Josep, (1976), «Comercio colonial e industrialización: una reflexión sobre los origenes de la industria moderna en Cataluña», en NADAL-Tortella (edits.), Agricultura, comercio colonial y crecimiento económico en la España Contemporánea, Barcelo. na, pp. 358-365.

FuKaSA Wa, Katsumi (1987a): «Comerce et contrebande des indiennes en Provence dans la deuxième moitié du XVIIIe siècle», Annales du Midi, tomo 99 n. 178, pp. 175-192.

- (1987b): Toilerie et commerce du Levant. D'Alep a Marseille, París.

Garavaglia, J. C. (1986): «Los textiles de la tierra en el contexto colonial rioplatense: ¿Una revolución industrial fallida?, Anuario del IEHS, I (Tandil), pp. 45-87.

Garavaglia, J. C., y WENTZEL, C. (1989): «Un nuevo aporte a la historia del textil colonial: los ponchos frente al mercado porteño, 1750-1850», Anuario del IEHS, IV, pp. 211-241.

GarCIA-BaQuero, Antonio (1974): «Comercio colonial y producción industrial en Cataluña a fines del siglo xviII», en L. Nadal y G. Tortella (edits.), Agricultura, comercio colonial y crecimiento económico en la España contemporánea, Barcelona, pp. 268-294.

- (1991): «La industria algodonera catalana y el libre comercio. Otra reconsideración», Manuscrits n. 9, pp. 13-40.

Garcla Rodriguez, M. (1994): «El monto de la trata hacia Cuba en el siglo Xvili, en C. Naranjo y T. Mallo (eds.), Cuba, la perla de las Antillas. Actas de las I Jormadas sobre "Cuba y su bistoria", Madrid, pp. 297-312.

IgLesias, J. J. (1991): Una ciudad mercantil en el siglo xvII. El Puerto de Santa María. Granada.

INIKORI, J. E. (1990): «Slavery and the Revolution in Cotton Textile Production in England», Social Sciences History, 14, pp. 343-379.

- (1992): «Slavery and the Revolution in Cotton Textile Production in England», en J. E. INikori y S. L. Engerman (eds.), The Atlantic Slave Trade. Effects on Economies, Societies, and Peoples in Africa, the Americas, and Europe, Durham, pp. 145.182.

IZARD, M. (1976): «Comercio libre, guerras coloniales y mercado americano», en NADAL y TORTElla (edits.), Agricultura, comercio colonial y crecimiento económico en la España Contemporánea, Barcelona, pp. 295-321.

KERRIDGE, E. (1985): Textile Manufactures in Early Madern England, Manchester.

LIPP, L. (1793): Guide des Négotiants, Montpellier (2 vols.). 
MaLuQueR De Motes, Jordi (1977): El socialismo en España, 1833-1868, Barcelona.

MarTin CoRrales, E. (1988): Cataluña y el mercado americano. Las exportaciones catalanas a Indias (1756-1778). Trabajo de investigación inédito.

MaRTinez Shaw, C. (1976): «Los origenes de la industria algodonera y el mercado colonial», en NADAl-Tortella (edits.), Agricultura, comercio colonial y crecimiento económico en la España contemporánea, Barcelona, pp. 243-267.

- (1981): Cataluña en la Carrera de Indias, 1680-1756, Barcelona.

- (1982): «El comercio español a fines del Antiguo Régimen», en España a finales del siglo XVIII, Tarragona, pp. 47-58.

— (1986). «Sobre el comerç català amb Amèrica al segle XVI», en 2nes Jornades $d E s-$ tudis Catalano-Americans, Barcelona, pp. 33-39.

- (1987): «El libre comercio y Cataluña: contribución a un debate», en El comercio libre entre España y América Latina, 1765-1824, pp. 43-52, Madrid.

Menegus Borneman, M. (1994): «La Producción y el Consumo Indígena en el Mercado de Toluca a fines del periodo colonial», comunicación a la sección Pautas de consumo en Hispanoamérica desde el siglo XVI, del 48 Congreso Internacional de Americanistas (Estocolmo).

Money, M. (1983): Los obrajes y el comercio en la Audiencia de Charcas, La Paz.

MoRIN, C. (1979): Michoacán en la Nueva España del siglo xvill. Crecimiento y desigualdad en una economía colonial, México.

Musset, A. (1988): «La conquesta del mercat peninsular durant la segona meitat del segle XVIII: l'exemple de la casa $\mathrm{F}_{c}$ Ribas i Cia (1766-1783)», Segon Congrés d'Història Moderna de Catalunya, Pedralbes, 8 , I.

NADAL, J. (1970): «La economía española, 1829-1931», en El Banco de España. Una historia económica, pp. 317-417.

- (1975): El fracaso de la revolución industrial en España, 1814-1913, Barcelona.

- (1991a): «La indústria cotonera», en J. Nadal (dir.), Història Econòmica de la Catalunya Contemporània, Enciclopèdia Catalana, Barcelona.

— (1991b): «Sobre l'entitat de la indianeria barcelonina del set-cents. Nota suggerida per la lectura d'un article d'Alexandre Sánchez», Recerques 24, pp. 180-186.

NorTH, Douglass C. (1991): «Institutions, Transaction Costs, and the Rise of Merchant Empires», en J. D. TrACY (edit.), The Political Economy of Merchant Empires. State power and World Trade, 1350-1750, pp. 22-40, Cambridge.

O'Brien, P.; Griffiths, T., y HunT, O. (1991): «Political Components of the Industrial Revolution: Parliament and the English cotton textile industry, 1660-1774», Economic History Review, XLIV, 3 pp. 395-423.

Oliva Melgar, J. M. (1987): Cataluña y el comercio privilegiado con América en el siglo Xvill. La Real Compañia de Comercio de barcelona a Indias, Barcelona.

POLLARD, Sidney (1991): «Regional Markets and National Development», en M. BERG (edit.), Markets and Manufacture in Early Industrial Europe, pp. 29-56, Londres-Nueva York.

Postma, J. M. (1990): The Dutch in the Atlantic Slave Trade 1680-1815, Cambridge.

RICHARDSON, D. (1987): "The Slave Trade, Sugar, and British Economic Growth, 1748 1776», Joumal of Interdisciplinary History, XVII: 4, pp. 739-769.

SÁNCHEZ, A. (1989), «L'estructura comercial d'una fàbrica d'indianes barcelonina: Joan Rull i Cia. (1790-1821)», Recerques, 22, pp. 9-24.

- (1992): «La indianeria catalana: ¿mito o realidad?, Revista de Historia Industrial, 1, pp. 213-232. 
SHEPHERD, James F. (1988): «British America and the Atlantic Economy», en R. HoFf. man; J. J. McCusker; R. R Menard y P. J. Albert (edits.), The Economy of Early America. The Revolutionary Period (1763-1790), pp. 3-43, Charlottesville.

Solow, Barbara L. (1991): «Introduction», en B. Solow (edit.), Slavery and the Rise of the Allantic System, Cambridge, pp. 1-20.

STEIN, S. J. (1974): «Reality in Microcosm; The Devate over Trade with America, 17851789», Historia Ibérica, I, pp. 105-123.

SteIN, R. L (1979): The French Slave Trade in the Eighteenth Century. An Old Regime Business, Wisconsin.

TATEISHI, H. (1989): «El Reglamento de Comercio Libre (1778) y la economía española", Studies in the Mediterranean World, Past and Present (Tokio), vol. XII, pp. 73-80.

Thomson, J. K. J. (1989): «The Catalan Calico-Printig Industry Compared Internationaly", Anuari de la Societat Catalana d'Economia, vol. 7, pp. 72-95.

- (1990): La indústria d'indianes a la Barcelona del segle XVIII, Barcelona.

- (1992): A Distinctive Industrialization. Cotton in Barcelona 1728-1832, Cambridge.

Tornero Tinajero, P. (1994): «El suministro de mano de obra esclava en Cuba. Estado español y oligarquía criolla», en C. NARAnjo y T. MALlo (eds.), Cuba, la perla de las Antillas, Madrid, pp. 313-334.

TORRas Elfas, J. (1984): «Especialización agricola e industria rural en Cataluña en el siglo XVIII», Revista de Historia Económica, n. 3, pp. 113-127.

(1987a): «Fabricants sense fäbrica. Estudi d'una empresa llanera d'Igualada (17261765)», Recerques, 19, pp. 145-160.

(1987b): «Los mercados de una empresa pañera catalana en la segunda mitad del siglo xviII. La casa Torelló de Igualada, 1759-1796», comunicación presentada al XII Simposio de Análisis Económico, Barcelona.

(1989): «Mercados españoles y auge textil en Cataluña en el siglo xvin», en $\mathrm{Ha}$ ciendo bistoria. Homenaje al Profesor Carlos Seco, Madrid.

(1991): «The Old and the New. Marketing Networks and Textile Growth in

Eigthteenth Century Spain», en M. BERG (edit.), Markets and Manufactures in Early Industrial Europe, Londres, pp. 93-113.

Travis, William P. (1964): The Theory of Trade and Protection, Cambridge, Mass.

VICENS VIVES, J. (1979) 4. a: Coyuntura económica y reformismo burgués, Barcelona.

Voltes Bou, P. (1964): Catalunya i la Llibertat de comerç amb Amèrica, Barcelona.

VILLIERS, P. (1991): «The Slave and Colonial Trade in France just before the Revolution»,

en B. L. Solow (ed.), Slavery and the Rise of Atlantic System, Harvard, pp. 210-236. 